\title{
Influence of Wind on Crop Canopy Reflectance Measurements
}

\author{
D. LORD and R. L. DESJARDINS
}

LRRI, Research Branch, Agriculture Canada, Ottawa, Canada KIA OC6

P. A. DUBÉ

Department of Phytology, Faculty of Agricultural Sciences and Food University Laval, Québec, Canada G1K 7P4

\begin{abstract}
Remote sensing techniques of measuring red and far-red crop canopy reflectance are frequently used to estimate crop canopy characteristics. The variability introduced in reflectance data from nonvegetative factors such as wind decreases the usefulness of the techniques. The objective of this study was to quantify and minimize the variability from wind on spectral reflectances. Red and far-red reflectances were acquired above wheat, barley, and alfalfa canopies throughout days of changing wind conditions. Periods of $312 \mathrm{~s}$ with little changes in irradiance values were used for the analysis. Wind had negligible effect on reflectances of a short canopy such as cut alfalfa, while it had a significant effect on reflectances from canopies with a higher vertical structure, particularly during gusty conditions. Within the windy and calm periods, extreme values of spectral reflectance differed by $60 \%$ and $12 \%$, respectively, in the red, and by $40 \%$ and $8 \%$ in the far-red for the barley canopy. For the compact and dense canopy structure of alfalfa, these differences reached a maximum of $10 \%$ under windy conditions in both spectral regions. The plant canopy architecture, the wind conditions, and the spectral regions all affected the magnitude of the influence of wind on crop canopy spectral reflectances. The mean reflectance of a canopy overestimated the true reflectance by $2-4 \%$ while the use of the median reduced this overestimation. Sampling requirements for this sensor are evaluated, and the possibility of decreasing either the sampling rate or the sampling period is discussed.
\end{abstract}

\section{Introduction}

Spectral reflectances collected using remote sensing instruments from ground platforms such as tripod, boom and movable rack are often used to develop empirical relationships to estimate plant canopy parameters related to crop growth, development and yield (Jackson et al., 1980). In general, the accuracy of these estimates is reduced by the errors in the measurements of field canopy reflectances used to develop the model (Goel et al., 1984), particularly if the environmental measuring conditions differ from one reflectance measurement to another (Richardson, 1981; Crist, 1984). Develop- ment of algorithms to perform adequately over broad regions or successive growing seasons must then take into account all the external factors causing deviation in plant canopy spectral patterns (Crist, 1984).

The effects of wind on the canopy geometry, that is, on the orientation of plant parts and on the amount of soils and stems reflecting through the canopy, vary with its speed, the architecture of the vegetation, and the wavelength of interest (Rao et al., 1979; Lord et al., 1983). When wind is strong enough to introduce either leaf fluttering or stem bending, the nonvegetative variability introduced in the plant canopy spectral re- 
flectance measurements can mask the variability arising from the vegetative factors. This in turn reduces the usefulness of these measurements for estimating plant canopy parameters (Jackson et al., 1980; Tucker et al., 1980). Errors introduced by the wind will not be eliminated through the use of linear combinations such as the near-infrared-to-red reflectance ratio, because its effects on canopy reflectances can differ between spectral regions (Rao et al., 1979). The objectives of this paper are to demonstrate the influence of wind on plant canopy spectral reflectance measurements and to suggest ways of eliminating most of its influence. Sampling requirements are also discussed.

\section{Materials and Methods}

Three days of data collected on wheat (6 July), barley ( 7 July), and alfalfa (9 July) crops at the Central Experimental Farm in Ottawa, Ontario, Canada, during the summer of 1982 were used to analyze the effect of wind on crop canopy spectral reflectance measurements. Crops were planted in $10 \mathrm{~m}$ long by $8 \mathrm{~m}$ wide plots on a fertilized Rubicond sand soil. Wheat (Triticum aestivum L. var. Pitic 62) and barley (Hordeum vulgare L. var. MasseyBreeder no. 2) were planted in NNW-SSE rows $0.18 \mathrm{~m}$ apart, while alfalfa (Medicago sativa L. var. Saranac) was planted in very narrow rows in order to obtain a canopy without rows. Wheat was at the beginning of flowering with a height of $0.8 \mathrm{~m}$ and LAI of 1.1, whereas barley was at the milky-mealy ripe stage of growth with a height of $1.0 \mathrm{~m}$ and LAI of 1.5 . The west half of the alfalfa plot was at the
$10 \%$ flower stage of growth with a height of about $1.0 \mathrm{~m}$ and LAI of 2.5 , while the east half was cut the day before the reflectance measurements were collected.

The radiometric data was collected from a nadir view angle using a spectroradiometer, at a height of $3 \mathrm{~m}$, with four different filters of fixed central wavelength peaks of transmission with bandwidth of $10 \mathrm{~nm}$ (Brach et al., 1983). The central peaks of the filters were in the far-red $(790 \mathrm{~nm}$ and $739 \mathrm{~nm})$ and the red $(675 \mathrm{~nm}$ and $647 \mathrm{~nm})$ regions. The energy at these wavelengths is known to be scattered and absorbed within the leaf cellular structures of green plants (Knipling, 1970) and important for plant morphogenesis (Cathey and Campbell, 1980). For each filter, a timing mechanism within the spectroradiometer allows $2 \mathrm{~s}$ for the measurement of the reflected radiation within an $8^{\circ}$ field of view, followed by another $2 \mathrm{~s}$ for the measurement of the hemispherical incident radiation. The ratio of the reflected to the incident radiation for each wavelength band gives the hemispherical-conical reflectance specific to the optical geometry of this instrument (Nicodemus et al., 1977). The time constant of the sensor, which is approximately $100 \mathrm{~ms}$, allows the measurements of all fluctuations in reflectance as long as enough data points are recorded.

Simultaneous to these spectral measurements, meteorological conditions were monitored at a meteorological station $500 \mathrm{~m}$ away. On each of the three days studied, a mean hourly minimum windspeed of $1-1.5 \mathrm{~m} \mathrm{~s}^{-1}$ was reached early in the morning, followed by a progressive increase of the mean hourly windspeed which occurred around midday with a 
maximum of 3.0, 5.0, and $4.5 \mathrm{~ms}^{-1}$ for 6 , 7 , and 9 July, respectively. In addition to this information, the presence or the absence of gusts and the relative magnitude of wind fluctuations were continuously noted. No direct coupling of windspeed and reflectance measurements were attempted because the information obtained would not have justified the high frequency the data would have needed to be recorded (Desjardins et al., 1973).

The method used to collect the reflectance data reduces most of the variability which could be introduced by factors other than wind in the spectral reflectance measurements. To eliminate the soil and crop canopy variability, the spectroradiometer remained stationary above the same section of the experimental plots for all the measuring period. The variability introduced by the continuous changes in solar elevation and azimuth angles was minimized by grouping the data into short time periods of $312 \mathrm{~s}$. To minimize the variability caused by changing irradiation conditions, only sunny periods with constant irradiance were retained. These periods were identified by compiling the deviation from the mean irradiance for each irradiance value collected within a given period. The sunny periods with all the deviations from the mean irradiance near zero percent were the only ones kept for the analysis.

The division between calm and windy periods followed a method similar to that used to separate out sunny from cloudy periods but with reflectance data instead of irradiance data. Small deviations from the mean reflectance for the majority of the reflectance data indicate calm conditions while high deviations signify windy conditions. Verification of this assumption was made with the wind data and field notes.

\section{Results and Discussion}

Influence of wind on

plant canopy spectral reflectances

The maximum deviation from the mean reflectance found in red and far-red spectral reflectances collected above wheat within a period of $312 \mathrm{~s}$ under calm conditions is less than $4 \%$ [Fig. 1(A)]. The dotted lines drawn on the same figure confirm that the sky conditions for this specific period were uniform since the highest deviation from the mean irradiance does not exceed $1 \%$. When large fluctuations in deviations from the mean irradiance are found for another period of calm conditions, extreme values of spectral reflectances collected in this period differ by as much as $40 \%$ in both spectral regions [Fig. 1(B)].

Wind can also decrease the usefulness of plant canopy spectral reflectance measurements for estimating some crop canopy parameters (Tucker et al., 1980). By setting individual plants in motion and by introducing variations in the leaf inclination-azimuth angle distribution, wind continuously changes the geometry and the electromagnetic response of the canopies (Kimes and Kirchner, 1983). Two spectral reflectances measured closely in time may show different values. The magnitude of the fluctuations vases with canopy architecture. Over short vegetation such as freshly cut alfalfa, the presence of wind causes negligible variations in reflectance measurements. All the deviations from the mean reflectance calculated for one specific sunny period of 

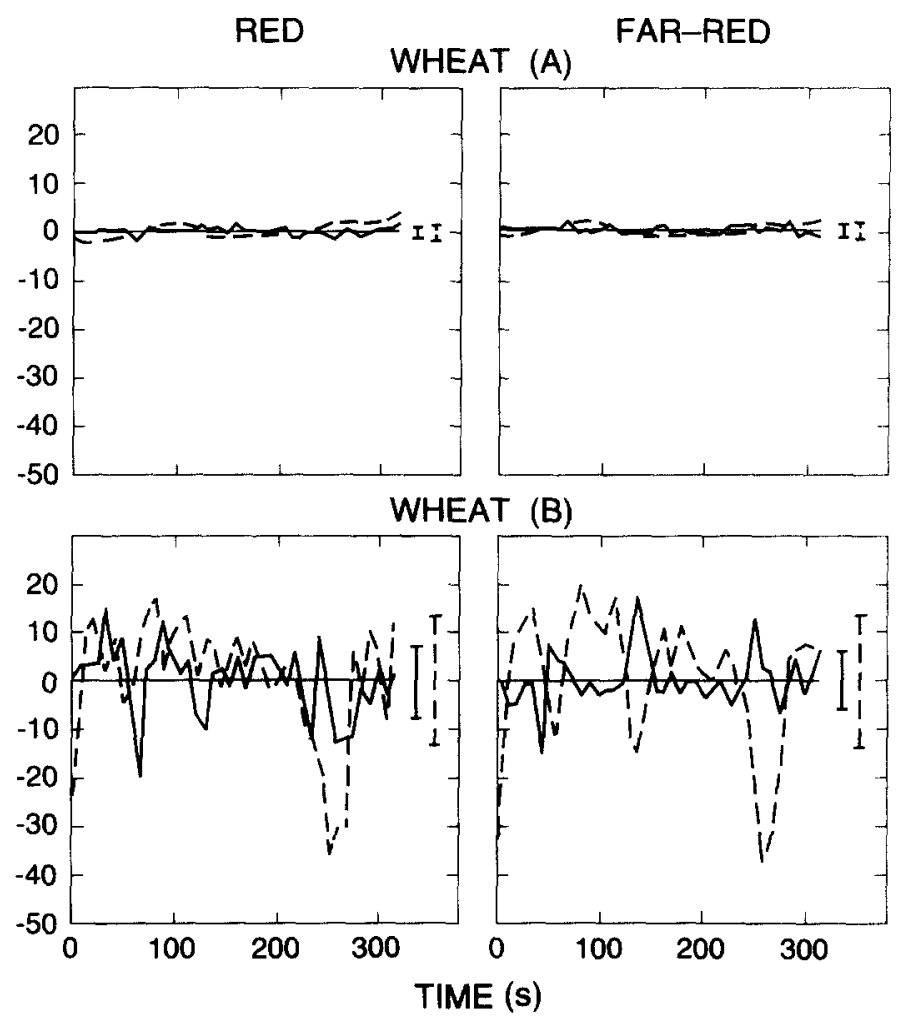

FIGURE 1. Deviation of the irradiance (-+-) and reflectance (-) from their means for a wheat canopy during calm clear conditions at solar elevation angle of $55^{\circ}(\mathrm{A})$ and during calm but variable irradiance conditions at solar elevation angle of $63^{\circ}$ (B). Bars denote the standard deviations.

$312 \mathrm{~s}$ remained near zero [Fig. 2(A)]. When the reflectance measurements were collected at approximately the same time over $1.0 \mathrm{~m}$ high alfalfa, differences up to $10 \%$ occurred between extreme values of spectral reflectances [Fig. 2(B)]. The larger variability caused by wind in both red and far-red spectral regions is also indicated by the higher standard deviations found for the reflectance data collected over the alfalfa [Figs. 2(A),(B)]. For crops planted in rows and having a canopy architecture less dense and compact than alfalfa, the differences between extreme values of spectral reflectances reach $60 \%$ and $35 \%$ for the red and the far-red regions, respectively [Fig. 2(C)]. The higher standard deviations found in both spectral regions for the reflectance data collected over barley confirm the greater influence of wind on this crop compared to alfalfa. The possibility for wind to more easily set each individual plant in motion when the canopy possesses both a well-developed vertical structure and plants spaced apart to allow stem bending and leaf fluttering can account for these higher amounts of nonvegetative variability.

For barley, differences between extreme values of red reflectance during a sunny 312 s period drop from a maximum of $60 \%$ during windy conditions [Fig. $2(\mathrm{C})]$ to a maximum of $12 \%$ during relatively calm conditions (Fig. 3). In the latter, leaf fluttering was still present but 


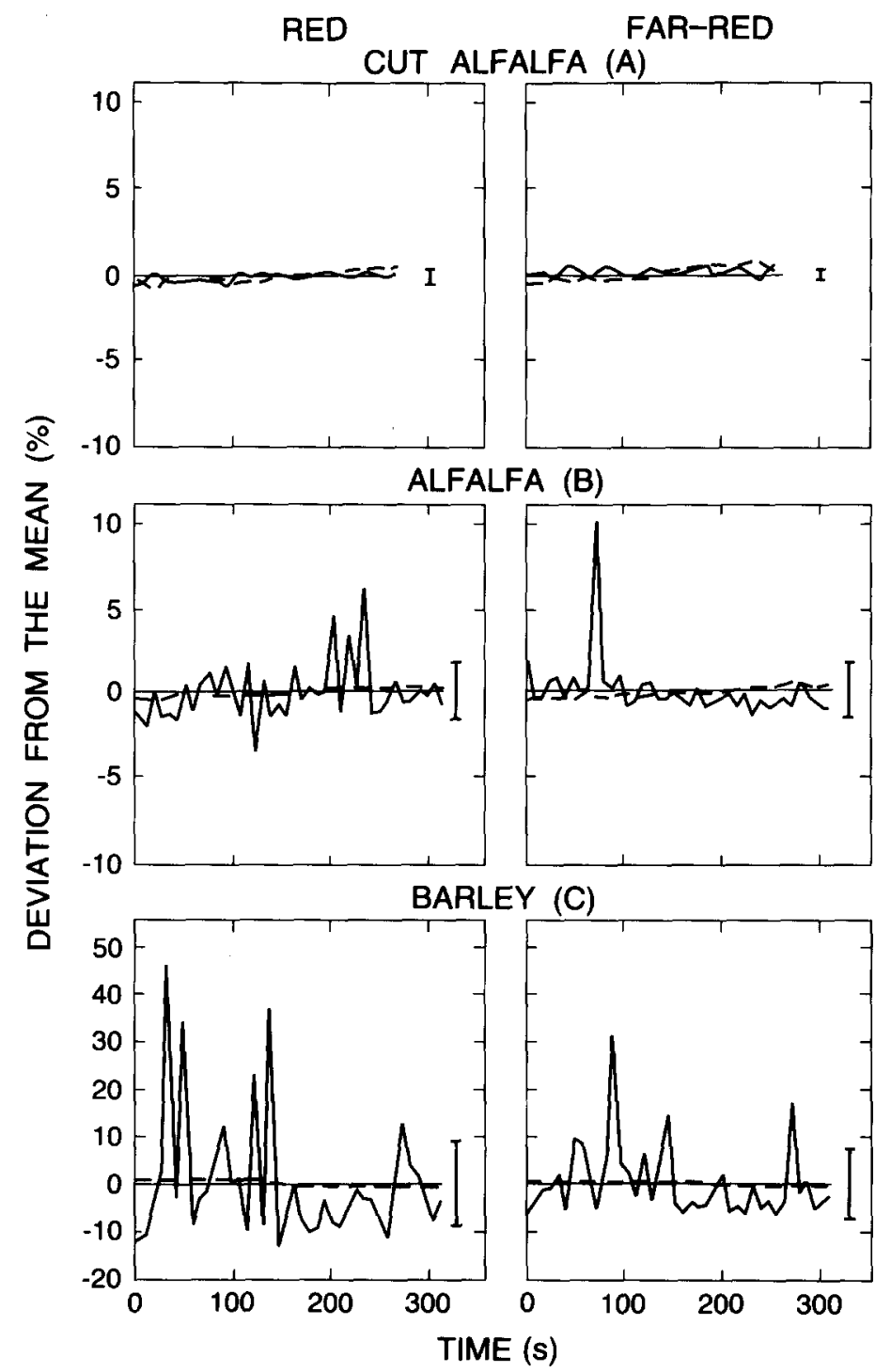

FIGURE 2. Same as Fig. 1 but for cut alfalfa (A), alfalfa (B) and barley (C) during gusty conditions at solar elevation angle of $56^{\circ}, 58^{\circ}$, and $62^{\circ}$, respectively.

stem bending was almost absent; under windy conditions, motions by individual plants were detected. This result demonstrates two points. First, the stem bending movement introduces larger fluctuations in spectral reflectances than leaf fluttering. Secondly, the strength of the wind and the importance of its fluctua- tions influence the amount of nonvegetative variability introduced by this factor in a plant canopy having a flexible architecture such as barley.

Differences between extreme values of far-red reflectances collected over barley also occur; however their magnitudes are smaller than those found for the red re- 


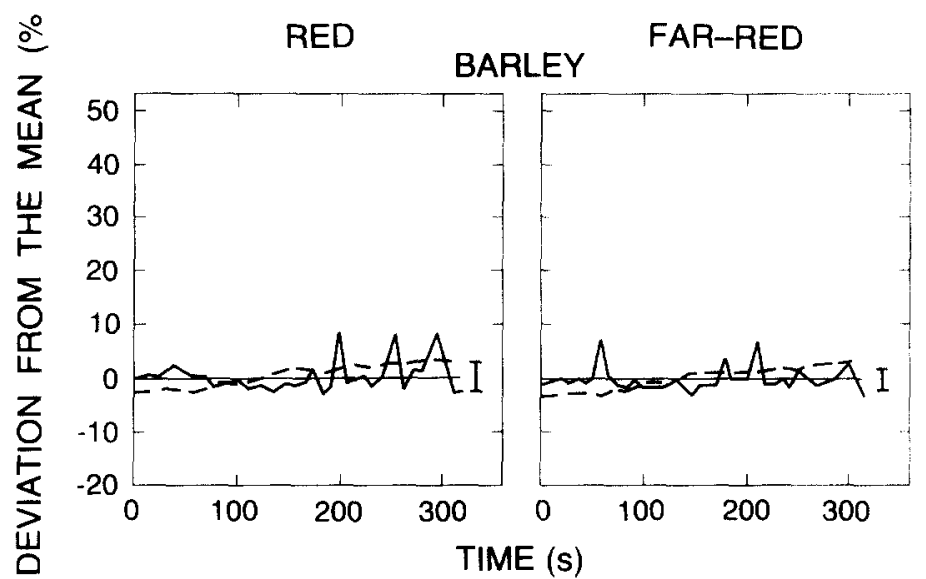

FIGURE 3. Same as Fig. 1 but for barley during calm conditions at solar elevation angle of $35^{\circ}$

gion [Figs. 2(C) and 3]. This spectral dissimilarity was expected since the red canopy reflectances are known to be more sensitive to wind than the far-red ones (Rao et al., 1979). This higher sensitivity of the red region is probably caused by the strong energy absorption by green plants in this spectral region.

\section{Estimation of the representative plant canopy spectral reflectance}

The deviations from the mean reflectance presented in Figs. 2(B),(C) demonstrate that, under windy conditions, the possibility of measuring a spectral reflectance value which greatly differs from the real reflectance of a crop canopy at its normal position exists for some canopies. Visual analysis of these fluctuations shows that the greatest deviations from the mean reflectance for one given windy period are usually found in the positive direction. Examples of the frequency distribution of the deviations from the mean reflectance are shown in Fig. 4. For flexible species such as barley, the highest frequency always appear either in the interval of deviations of $-5--3 \%$ or
$-3--1 \%$, whatever the sun angle [Figs. 4(A),(B)]. As expected from the previous analysis, the far-red reflectances usually show smaller deviations from the mean.

If it is assumed that the more frequent spectral reflectances should correspond to the value which would have been measured under calm conditions, it can be concluded that wind increases the mean reflectance when data is collected every eight seconds during a 312 s period. To a first approximation, an error of about $5 \%$ seems small. However, Goel et al. (1984) estimated that measuring reflectances with an accuracy of less than $3 \%$ means that little can be said about the estimated value of a canopy parameter such as LAI. Moreover, if these data are used to develop an algorithm for subsequent estimations of LAI, the model could be inaccurate because of these errors in the reflectance measurements (Crist, 1984).

For less flexible species such as alfal$\mathrm{fa}$, the highest frequency occurs in the $-1-1 \%$ deviation interval, but there are still more negative deviations than positive ones (Fig. 4E). For nonflexible canopies such as cut alfalfa or for the periods of calm conditions over any plant 


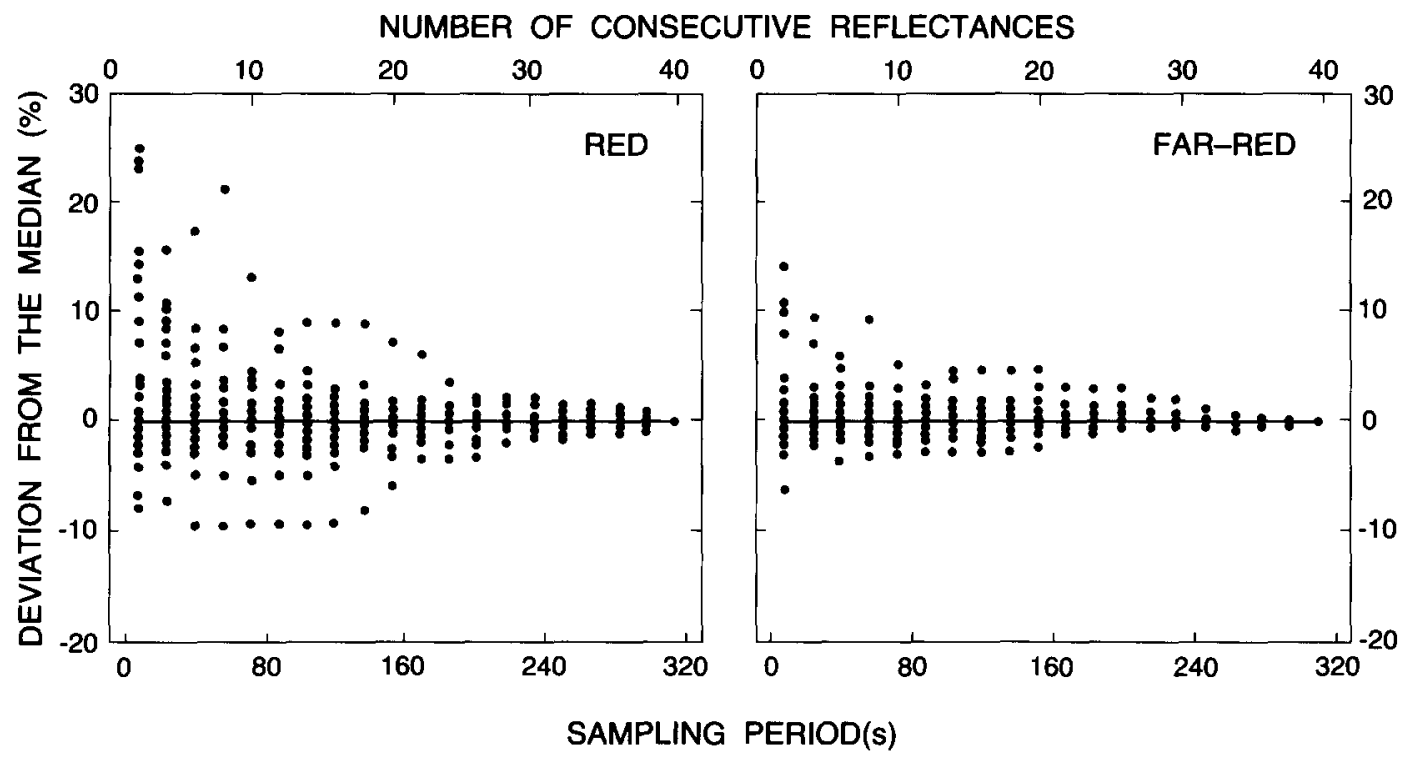

FIGURE 4. Frequency distributions of the deviation from the mean red and far-red (:::) reflectance for different species during sunny periods characterized by different wind conditions and solar elevation angles.

canopies, the highest frequency is always retrieved in the interval centered on $0 \%$ deviation [Figs. 4(C),(D), (F), (H)]. As expected from the results previously shown in Figs. 2(A), (B), and 3, the use of the mean reflectance does not introduce significant overestimation of the real spectral reflectance of a canopy location for these types of canopies under windy conditions and for all canopies under calm conditions.

The frequency distributions of the de1 . viations from the mean reflectance follow more a binomial distribution than a normal one for flexible canopies. The application of the test of Kolomogorov and Smirnov (SAS, 1979) on these data gives probabilities under 0.01 of finding a normal distribution. The wind skews the distribution of the deviations, and either the median or the mode appears a better estimator of the reflectance population than the arithmetic mean itself. For barley the medians of the reflectances collected over the windy periods are $2-4 \%$ smaller than their respective means. However, there are almost no differences between the medians and the means for less flexibles canopies or for calm periods (Table 1). The overestimation of the plant canopy spectral reflectances seems minimized by using the median instead of the arithmetic mean. The fact that the deviations from the mean reflectance for the medians usually falls within the interval showing the highest frequency of reflectance data supports this affirmation (Table 1 and Fig. 4). It may also be noted that the use of the median when wind conditions are calm or when canopies are less flexible does not introduce important deviations from the mean reflectance ( $\mathrm{Ta}$ ble 1).

\section{Analysis of sampling}

It is important to evaluate the number of measurements needed to accurately measure the true spectral reflectances of a flexible canopy under windy conditions. Approximately 40 windspeed measure- 
TABLE 1 Deviations of the Median from the Reflectance Mean (DMRM) for Different Species and Wind Conditions at Different Solar Elevation Angles

\begin{tabular}{|c|c|c|c|c|c|c|}
\hline \multirow{3}{*}{$\frac{\text { SPECIES }}{\text { Cut alfalfa }}$} & \multicolumn{6}{|c|}{ DMRM (\%) For RED (FAR-RED) SPECTRAL Recion } \\
\hline & \multicolumn{2}{|c|}{$\begin{array}{c}\text { UNDER WINDY CONDITIONS } \\
\text { WITH GUSTS }\end{array}$} & \multicolumn{2}{|c|}{$\begin{array}{c}\text { SOLAR ELEVATION } \\
\text { ANGLE ( }\end{array}$} & \multicolumn{2}{|c|}{$\begin{array}{c}\text { UNDER } \\
\text { CALM CONDITIONS }\end{array}$} \\
\hline & 0.12 & $(0.11)$ & $>47$ & $<67$ & 0.17 & $(0.09)$ \\
\hline \multirow[t]{2}{*}{ Alfalfa } & -0.27 & $(-0.48)$ & $<58$ & $>51$ & -0.05 & $(0.03)$ \\
\hline & -0.69 & $(-0.43)$ & $>63$ & $<67$ & -0.21 & $(-0.10)$ \\
\hline \multirow[t]{5}{*}{ Barley } & -4.17 & $(-1.20)$ & $>32$ & $<28$ & -0.35 & $(-1.34)$ \\
\hline & -3.75 & $(-0.82)$ & $>42$ & $<31$ & -0.50 & $(-0.77)$ \\
\hline & -3.22 & $(-1.19)$ & $>56$ & $<37$ & -0.30 & $(-0.13)$ \\
\hline & -1.99 & $(-1.20)$ & 64 & & & \\
\hline & -4.11 & $(-2.12)$ & 67 & & & \\
\hline \multirow[t]{2}{*}{ Wheat } & & & & 47 & -0.09 & $(0.02)$ \\
\hline & & & & 58 & -0.18 & $(0.45)$ \\
\hline
\end{tabular}

ments per second are required to detect all fluctuations contributing to the horizontal wind (Kaimal et al., 1972; Desjardins et al., 1978). However, these high frequency fluctuations lead to leaf fluttering and stem bending which do not occur at a frequency as high as the windspeed (Desjardins et al., 1973). In our experiments, one reflectance measurement was made for each spectral region every $8 \mathrm{~s}$. The sampling method used in this study must be evaluated with respect to the needs of measuring as many as 40 consecutive spectral reflectances for determining under windy conditions the real reflectance value of a specific location within a flexible canopy. To examine the length of the sampling period required, 46 sunny periods of $312 \mathrm{~s}$ obtained within a complete day of reflectance measurements above the same location of a barley field are selected in order to regroup different types of windy conditions, some of them including the presence of strong gusts while others are entirely characterized by calm conditions. The 46 reference medians obtained from these periods are compared to those calculated using two methods of sampling.

One method consists of reducing the number of reflectance measurements per minute during an entire 312 s sampling period. If one spectral reflectance measurement every $8 \mathrm{~s}$ during $312 \mathrm{~s}$ gives 40 spectral reflectance measurements and a sampling rate of 7.5 data per minute, one spectral reflectance measurement at every $16,32,40,48,56,64,72,104,152$, and $312 \mathrm{~s}$ during a period of $312 \mathrm{~s}$ will respectively give $20,10,9,8,7,6,5,4,3$, and 2 spectral reflectance measurements and corresponding sampling rates of 3.75 , $1.83,1.50,1.25,1.07,0.94,0.84,0.58$, 0.39 , and 0.19 . A median is calculated for each one of these sampling rates applied to each one of the 46 periods, each result being compared to their respective reference median in order to compile the deviations between them. The 46 deviations for each one of those 11 sampling rates are reported in Fig. 5 for both spectral regions. The results confirm the increasing probability of obtaining relatively large deviations from the reference medians under lower sampling rates. However, our maximum sampling rate of 7.5 samples per minute may be easily reduced by 2 without loss of accuracy. This supports the hypothesis that a higher sampling rate within the actual length of the sampling period would not change the value of the reference median reflectance. Less than four samples per minute 
NUMBER OF REFLECTANCES

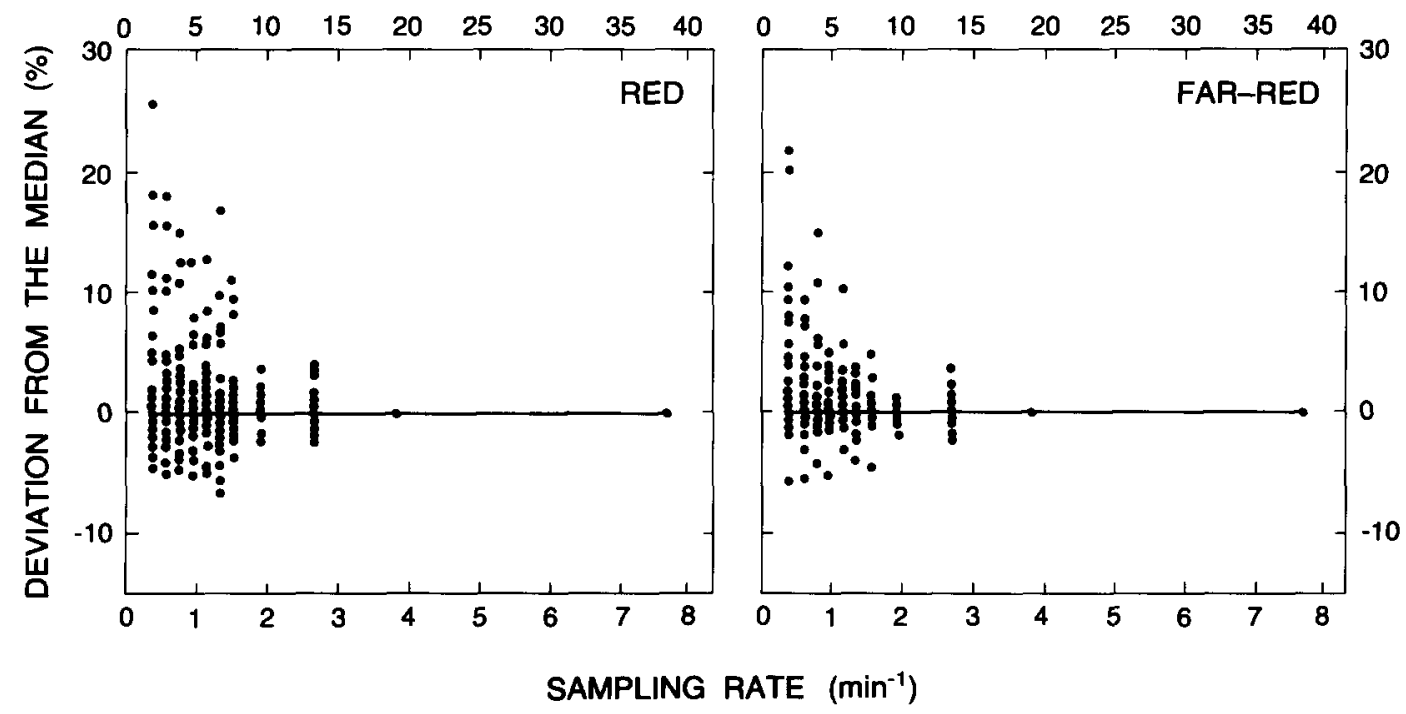

FIGURE 5. Deviation of the reflectance from its median for various sampling rates applied to sunny period of $312 \mathrm{~s}$.

over a $312 \mathrm{~s}$ sampling period increases the probability of obtaining large deviations from the real reflectance value. To compensate for this low sampling rate, the sampling period would have to be lengthened.

Since 20 reflectance measurements collected at every $16 \mathrm{~s}$ during $312 \mathrm{~s}$ under windy conditions over barley seems adequate to determine the true reflectance of a specific location, a second method of sampling consists of evaluating whether these 20 measurements must be collected in a consecutive way without loss of accuracy due to the shortening of the sampling period from $312 \mathrm{~s}$ to $152 \mathrm{~s}$. The medians for different sequences of consecutive spectral reflectance measurements $(2,4,5,8, \ldots, 38)$ are calculated for each one of the previous 46 sampling periods. The deviations from their respective reference median are then compiled and plotted (Fig. 6). These results demonstrate two points: 1) for the same number of samples, fluctuations caused by a smaller sampling period are greater in the red spectral region, and 2) at least 30 consecutive reflectance measurements must be made every eight seconds to keep low deviations from median reflectance. This represents a sampling period of $240 \mathrm{~s}$ as compared to the original one of $312 \mathrm{~s}$.

This study confirms the large influence of wind on crop canopy spectral reflectances collected using remote sensing techniques from ground platforms. The sensitivity of a canopy to wind is, however, dependent on its geometrical configuration. There is also a spectral difference, red reflectances showing larger variability than far-red ones. The median was found to be a better estimator of the population of spectral reflectances collected under windy conditions above crop canopies sensitive to this factor.

The support of the Engineering and Statistical Research Service and the Crop Information Program of the Research Branch of Agriculture Canada is much appreciated. 

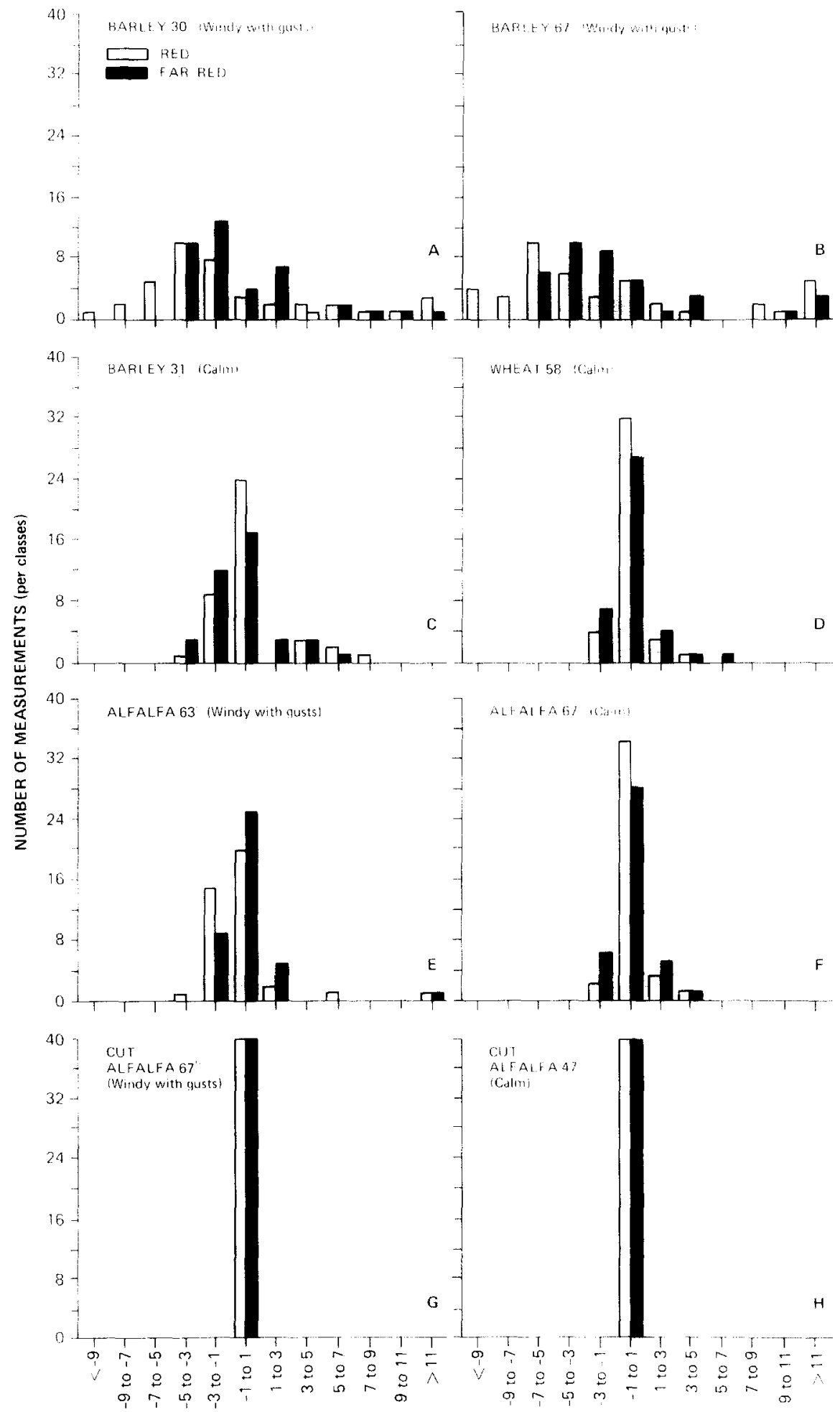

DEVIATIONS FROM THE MEAN REFLECTANCE (\%)

FIGURE 6. Deviation of the reflectance from its median for various lengths of sampling periods and a constant sampling rate of $7.5 \mathrm{data} / \mathrm{min}$. 


\section{References}

Brach, E. J., Poirier, P., Desjardins, R. L., and Lord, D. (1983), Multispectral radiometer to measure crop canopy characteristics, Rev. Sci. Instrum. 54(4):493-500.

Cathey, H. M., and Campbell, L. E. (1980), Light and lightning systems for horticultural plants, In Horticultural Reviews (Jules Janick, Ed.), AVI Publishing Co., Westport, CT, vol. 2, pp. 491-537.

Colwell, J. E. (1974), Vegetation canopy reflectance, Remote Sens. Environ. 3(3): 175-183.

Crist, E. P. (1984), Effects of cultural and environmental factors on corn and soybean spectral development patterns, $R e$ mote Sens. Environ. 14:3-13.

Desjardins, R. L., Sinclair, T. R., and Lemon, E. R. (1973), Light fluctuations in corn, Agron. J. 65(6):904-908.

Desjardins, R. L., Allen, L. H., and Lemon, E. R. (1978), Variations of carbon dioxide, air temperature, and horizontal wind within and above a maize crop, Boundary-Layer Meteorol. 14:369-380.

Goel, N. S., Strebel, D. E., and Thompson, R. L. (1984), Inversion of vegetation canopy reflectance models for estimating agronomic variables. II. Use of angle transforms and error analysis as illustrated by Suits' model, Remote Sens. Environ. 14:77-111.

Holben, B. N., Tucker, C. J., and Fan, C. J. (1980), Spectral assessment of soybean leaf area and leaf biomass, Photogramm. Eng. Remote Sens. 46(5):651-656.

Jackson, R. D., Pinter, P. J., Jr., Reginato, R. J., and Idso, S. B. (1980), Hand-held radiometry, Agricultural Reviews and Manual ARM-W-19, USDA, Science and Education Administration, Washington, DC.

Kaimal, J. C., Wyngaard, J. C., Izumi, Y., and Cote, O. R. (1972). Spectral characteristics of surface-layer turbulence, Quart. J. R.
Meteorol. Soc. 98:563-589.

Kimes, D. S., and Kirchner, J. A. (1983), Diurnal variations of vegetation canopy structure, Int. J. Remote Sens. 4:257-271.

Knipling, E. B. (1970), Physical and physiological basis for the reflectance of visible and near-infrared radiation from vegetation, Remote Sens. Environ. 1:155-159.

Lord, D., Dubé, P. A., Desjardins, R. L., and Brach, E. J. (1983), Variabilité introduite dans des mesures de réflectances spectrales de couverts végétaux agricoles par les facteurs état du ciel et vent, In Proc. Colloque International de signatures spectrales d'objets en télédétection, Bordeaux, France, pp. 277-285.

Nicodemus, F. E., Richmond, J. C., Hsia, J. J. Ginsberg, I. W., and Limperis, T. (1977), Geometrical considerations and nomenclature for reflectance, Monograph 160, National Bureau of Standards, Washington, DC, 52 pp.

Rao, V. R., Brach, E. J., and Mach, A. R. (1979), Effect on surface winds on the spectral signatures of crops, Agron. J. 71(3):515-518.

Richardson, A. J. (1981), Measurement of reflectance factors under daily and intermittent irradiance variations, Appl. Opt. 20(19):3336-3340.

SAS Institute Inc. (1979), SAS Users Guide Cary, NC, 494 pp.

Stoner, E. R., Baumgardner, M. F., Biehl, L. L., and Robinson, B. F. (1980). Atlas of soil reflectance properties, Agric. Exp. Stn. Res. Bull. No. 962, Purdue University, West Lafayette, IN.

Tucker, C. J., Holben, B. N., Elgin, J. H., Jr., and McMurtrey, J. E., III (1980). Relationship of spectral data to grain yield variation, Photogramm. Eng. Remote. Sens. 46(5):657-666.

Received 10 May 1984; revised 31 January 1985. 